\title{
Determination of salivary glucose in healthy adults
}

\author{
Maria-Sueli-Marques Soares ${ }^{1}$, Mário-Márcio-Vasconcelos Batista-Filho ${ }^{2}$, Marcele-Jardim Pimentel ${ }^{2}$, Isabe- \\ la-Albuquerque Passos ${ }^{3}$, Eduardo Chimenos-Küstner ${ }^{4}$
}

\author{
${ }^{1}$ Federal University of Paraíba (Brazil), Associate Professor of Oral Medicine \\ ${ }^{2}$ Federal University of Paraíba (Brazil), Students of Dentistry/ Scholars of the National Council for Research and Development \\ $(\mathrm{CNPq})$ \\ ${ }^{3}$ Federal University of Paraíba (Brazil), Post-graduate Student of Oral Medicine \\ ${ }^{4}$ University of Barcelona, Associate Professor of Oral Medicine, Faculty of Dentistry
}

Correspondence:

Rua Dr. Francisco Sarmento Meira,150/101

Bessa - João Pessoa- Paraíba - Brazil

Zip code: $58035-420$

bessa@mixmail.com

Received: 17/08/2008

Accepted: 07/06/2009

Soares MSM, Batista-Filho MMV, Pimentel MJ, Passos IA, ChimenosKüstner E. Determination of salivary glucose in healthy adults. Med Oral Patol Oral Cir Bucal. 2009 Oct 1;14 (10):e510-3.

http://www.medicinaoral.com/medoralfree01/v14i10/medoralv14i10p510.pdf

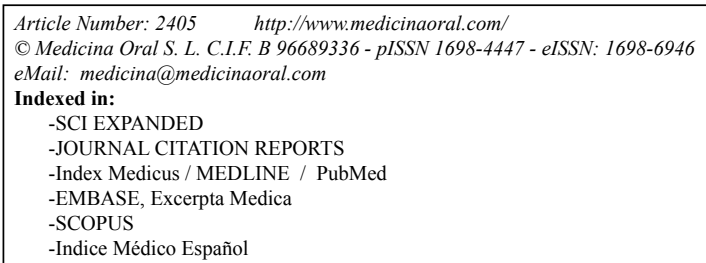

\begin{abstract}
Objectives: Our aim in this study was to determine the concentration of salivary glucose in healthy individuals and to compare it with the capillary glycemia. Study design: Samples of unstimulated whole saliva were collected from 63 non-diabetic patients. The concentration of salivary glucose and capillary blood was measured in all of the patients. The salivary glucose was determined by enzymatic method and spectrophotometry. The data was then analyzed using the Spearman correlation test, considering values of $\mathrm{p}<0.05$ to be significant. Results: The whole sample consisted of $47.6 \%$ males and $52.4 \%$ women, with an average age of $37.5 \pm 15.7$ years old. The average rates of unstimulated salivary flow were $0.41 \pm 0.21 \mathrm{ml} / \mathrm{min}$ among males and $0.31 \pm 0.15 \mathrm{ml} / \mathrm{min}$ among females. No significant difference was found based on these results $(\mathrm{p}=0.078)$. The average blood glucose among the males studied was $100.05 \pm 13.51 \mathrm{mg} / \mathrm{dL}$, and among females, it was $99.5 \pm 13.9 \mathrm{mg} / \mathrm{dL}$. The average salivary glucose for the whole sample was $5.97 \pm 1.87 \mathrm{mg} / \mathrm{dL}$, with $5.91 \pm 2.19 \mathrm{mg} / \mathrm{dL}$ among males and $5.97 \pm 1.56 \mathrm{mg} / \mathrm{dL}$ among females, respectively, without presenting any significant differences $(\mathrm{p}=0.908)$. The concentration of salivary glucose did not present any statistically significant correlation with the capillary glycemia $(\mathrm{p}=0.732)$. Conclusions: The results suggest that the concentration of salivary glucose is not dependent on capillary glycemia and that the concentration of salivary glucose does not present significant differences between the measurements for males and females.
\end{abstract}

Key words: Saliva, salivary glucose, glycemia, oral diagnosis. 


\section{Introduction}

The concentration of some components of saliva may be associated with certain systemic illnesses, reflecting the hormonal, immunological, neurological, emotional, nutritional and metabolic states of the patient (1). Saliva is an organic fluid that is easy to collect by non-invasive methods and is not costly to preserve (2). These reasons prompt an interest in evaluating the possibility of using saliva as a diagnostic resource.

Glucose is a small molecule that diffuses easily through the membrane of the blood vessels, passing through the blood serum to the gingival fluid, by way of the gingival sulcus, and making its way to the saliva (3). Elevated levels of blood glucose may cause oral alterations such as: a higher incidence of cavities $(4,5)$, periodontal disease (5) and candidiasis (6). However, in the literature, we encounter a controversy regarding the relationship between the concentration of blood glucose and salivary glucose. Several authors show that an increase in the concentration of glucose in saliva has to do with glycemia (6-9); however, this relationship is not confirmed in other studies $(3,10-14)$.

Considering the limited amount of studies that evaluate the concentration of glucose in saliva and the controversy that exists in the relationship between salivary glucose and glycemia, in this study, we propose to determine the concentration of salivary glucose, comparing it with the capillary glycemia in healthy patients.

\section{Material and Methods}

The research project of this study was submitted for evaluation by the Human Research Ethics Committee of the Health Sciences Center at the Federal University of Paraíba (Brazil).

We selected 63 healthy patients (non-diabetic and without oral pathology), aged 18 years or more, who were non-smokers and not taking any medication. These patients were seen at the dental clinic of the Federal University of Paraíba/João Pessoa/Paraíba, in Brazil.

A medical history was collected from all of the patients, in addition to a sample of their unstimulated and stimulated salivary flows, and a capillary blood sample. The concentration of salivary glucose and blood glucose was determined for each of the samples collected.

\section{Determination of the unstimulated and stimulated salivary flow rates}

The unstimulated and stimulated salivary flow rates were determined by the method of spitting the saliva. Salivary flow was always measured between 9am and $12 \mathrm{pm}$, while the patient was fasting and had not carried out any oral hygiene at least 90 minutes before collecting the sample. In order to obtain the unstimulated salivary flow rate, the patient was asked to swallow the saliva present in the mouth and then to remain still without moving the tongue or swallowing the saliva for one minute. The patient spat the saliva into a glass tube every 60 seconds for a total of 5 minutes. In order to obtain the stimulated salivary flow rate, $2 \%$ acetic acid was applied to the back and tip of the tongue every 30 seconds for a total of 2 minutes. The patient then spat the saliva produced into a graduated tube every $60 \mathrm{sec}-$ onds (15). The saliva obtained was frozen in order to be preserved.

\section{Determination of the concentration of blood glucose} In order to determine the capillary glycemia, the soft flesh of the patient's index finger was cleaned with cotton and $70 \%$ alcohol. The patient's finger was then pricked with a disposable needle and a drop of blood was collected by applying slight pressure to the finger. The blood was placed on a reactive test strip for glucose and the concentration of glucose was determined by using a glucosimeter (ONE TOUCH ULTRA, by JOHNSON \& JOHNSON®), where the blood glucose is expressed in milligrams per deciliter $(\mathrm{mg} / \mathrm{dL})$.

\section{Determination of glucose in the unstimulated sali- vary flow}

The saliva was unfrozen and centrifuged at 3,500 rpm for 10 minutes. Immediately thereafter, $10 \mu 1$ of saliva was poured into an Ependoff tube, $1 \mathrm{ml}$ of enzymatic reagent was added (Human Glucose Color Kit from Bra$\left.\mathrm{zil}^{\circledR}\right)$ and the sample was blended into a homogeneous mixture. The standard solution (composed of $1 \mathrm{ml}$ of enzymatic reagent) and the white solution (composed of $1 \mu \mathrm{l}$ of white solution plus $1 \mathrm{ml}$ of enzymatic reagent) were prepared. The sample of saliva, the standard solution and the white solution were placed in a bain marie at $37^{\circ} \mathrm{C}$ for 5 minutes.

The reading of the absorbency of the saliva samples was performed using a UV-VIS spectrophotometer (ultraviolet and visible light) BECKMAN DU 640®, with a wavelength of $500 \mathrm{~nm}$. Each reading of the sample was performed twice.

The data obtained was subjected to a descriptive and comparative statistical study. In order to compare the measurements, the Spearman correlation test was used, where values of $p<0.05$ were considered significant.

\section{Results}

The sample of this study consisted of 63 non-diabetic patients, including $30(47.6 \%)$ males and $33(52.4 \%)$ females aged between 19 and 72 years; the average age was $37.5 \pm 15.7$ years old.

For the whole sample, the average unstimulated salivary flow rate was $0.35 \pm 0.22 \mathrm{ml} / \mathrm{min}$, with an average of $0.30 \pm 0.14 \mathrm{ml} / \mathrm{min}$ among females and $0.40 \pm 0.27 \mathrm{ml} / \mathrm{min}$ among males, without observing any statistically significant difference between the genders $(p=0.078)$. The 
Table 1. Averages, standard deviation and ratio of correlation between the salivary flow, salivary glucose and glycemia of the patients studied.

\begin{tabular}{|l|c|c|c|}
\hline & Males $(\mathbf{n}=\mathbf{3 0})$ & Females $(\mathbf{n = 3 3})$ & $\mathbf{p}$ \\
\hline $\begin{array}{l}\text { Unstimulated sali- } \\
\text { vary flow rate }(\mathrm{ml} / \\
\text { min) }\end{array}$ & $0.41 \pm 0.21$ & $0.31 \pm 0.15$ & 0.078 \\
\hline $\begin{array}{l}\text { Salivary glucose } \\
(\mathrm{mg} / \mathrm{dL})\end{array}$ & $5.91 \pm 2.19$ & $5.97 \pm 1.56$ & 0.908 \\
\hline Glycemia $(\mathrm{mg} / \mathrm{dL})$ & $99.5 \pm 13.9$ & $100.5 \pm 13.51$ & $0.001^{*}$ \\
\hline
\end{tabular}

* statistically significant

average stimulated salivary flow rate was $1.43 \pm 0.86 \mathrm{ml} /$ $\mathrm{min}$, with an average of $1.27 \pm 0.49 \mathrm{ml} / \mathrm{min}$ among males and $1.63 \pm 1.11 \mathrm{ml} / \mathrm{min}$ among females. This difference was not found to be statistically significant ( $p=0.107$ ). The capillary glycemia of the patients studied varied from $74 \mathrm{mg} / \mathrm{dL}$ to $124 \mathrm{mg} / \mathrm{dL}$, with an average of $93 \pm 12.6$ $\mathrm{mg} / \mathrm{dL}$. The average was $88.6 \pm 8.8 \mathrm{mg} / \mathrm{dL}$ among females, and $99.5 \pm 13.9 \mathrm{mg} / \mathrm{dL}$ among males, with a statistically significant difference $(\mathrm{p}=0.001)$. The average salivary glucose for the whole sample was $5.94 \pm 1.87$ $\mathrm{mg} / \mathrm{dL}$, with an average of $5.97 \pm 1.56 \mathrm{mg} / \mathrm{dL}$ among females and $5.91 \pm 2.19 \mathrm{mg} / \mathrm{dL}$ among males. These differences were statistically insignificant $(\mathrm{p}=0.908)$. The concentration of salivary glucose did not present any statistically significant correlation with the capillary glycemia $(p=0.732)$. However, we did observe a statistically significant correlation between salivary glucose and the unstimulated salivary flow rate $(\mathrm{p}=0.001)$. The average values, standard deviation and correlation of salivary flow, salivary glucose and glycemia of the sample studied are described below in Table 1.

\section{Discussion}

Knowledge of the components of saliva is important because they may indicate oral or systemic alterations, and it is also important because saliva may be a substitute for blood in lab tests for the diagnosis of illnesses. Several studies evaluate the concentration of glucose in the saliva of diabetic patients, yet few do so in healthy patients with the idea of determining a standard based on the results of healthy patients.

As for that regarding the concentration of salivary glucose, the average for the patients of this study was 5.94 $\mathrm{mg} / \mathrm{dL}$, very similar to the measurement of $5.57 \mathrm{mg} / \mathrm{dL}$ recorded by Di Gioia et al. (14). On the other hand, our results differ from those of Agha-hosseini et al. (12), who obtained an average salivary glucose measurement of $13.6 \mathrm{mg} / \mathrm{dL}$. One explanation for these differences may be the choice of certain study designs, as well as the diversity of the methods and criteria for selecting the samples $(11,16)$. We highlight that in this study, we have observed a statistically significant correlation be- tween the salivary flow rate and the concentration of salivary glucose, which indicates that it is also important to consider the average flow rate among the patients of the study sample. Karjalainen et al. (6) and Moore et al. (16) observed an opposite correlation between the concentration of glucose and the salivary flow. It is necessary to consider the type of flow: whether it is unstimulated or stimulated, and if it the whole salivary flow rate or the flow rate for a specific gland. In this study, the measurements were recorded with the whole unstimulated flow rate.

We have observed in this study that the modifications of the levels of capillary glycemia are not reflected in the saliva, which corroborated the results of Akanji et al. (13), as well as those of Di Giora et al. (14), who also evaluated the salivary glucose in healthy patients.

It is important to mention that even in studies on saliva in diabetic patients, several authors have not observed a correlation between salivary glucose and glycemia: for example, Carda et al. (11); Forbat et al. (10) ; Reuterving et al. (7) and Ben-Aryeh et al. (3).

Based on the results obtained from the sample studied, we can derive the following conclusions: the concentration of salivary glucose in the unstimulated salivary flow rate is not dependent on capillary glycemia and there is no statistically significant difference between the measurements recorded for males and females.

\section{References}

1. Mandel ID. The role of saliva in maintaining oral homeostasis. J Am Dent Assoc. 1989;119:298-304.

2. Dawes C. Considerations in the development of diagnostic tests on saliva. Ann N Y Acad Sci. 1993;694:265-9.

3. Ben-Aryeh H, Serouya R, Kanter Y, Szargel R, Laufer D. Oral health and salivary composition in diabetic patients. J Diabetes Complications. 1993;7:57-62

4. Pohjamo L, Knuuttila M, Tervonen T, Haukipuro K. Caries prevalence related to the control of diabetes. Proc Finn Dent Soc. 1988;84:247-52.

5. Twetman S, Johansson I, Birkhed D, Nederfors T. Caries incidence in young type 1 diabetes mellitus patients in relation to metabolic control and caries-associated risk factors. Caries Res. 2002;36:31-5. 6. Karjalainen KM, Knuuttila ML, Käär ML. Salivary factors in children and adolescents with insulin-dependent diabetes mellitus. Pediatr Dent. 1996;18:306-11. 
7. Reuterving CO, Reuterving G, Hägg E, Ericson T. Salivary flow rate and salivary glucose concentration in patients with diabetes mellitus influence of severity of diabetes. Diabete Metab. 1987;13:45762.

8. Belazi MA, Galli-Tsinopoulou A, Drakoulakos D, Fleva A, Papanayiotou PH. Salivary alterations in insulin-dependent diabetes mellitus. Int J Paediatr Dent. 1998;8:29-33.

9. Darwazeh AM, MacFarlane TW, McCuish A, Lamey PJ. Mixed salivary glucose levels and candidal carriage in patients with diabetes mellitus. J Oral Pathol Med. 1991;20:280-3.

10. Forbat LN, Collins RE, Maskell GK, Sönksen PH. Glucose concentrations in parotid fluid and venous blood of patients attending a diabetic clinic. J R Soc Med. 1981;74:725-8.

11. Carda C, Mosquera-Lloreda N, Salom L, Gomez de Ferraris ME, Peydró A. Structural and functional salivary disorders in type 2 diabetic patients. Med Oral Patol Oral Cir Bucal. 2006;11:E309-14.

12. Agha-Hosseini F, Dizgah IM, Amirkhani S. The composition of unstimulated whole saliva of healthy dental students. J Contemp Dent Pract. 2006;7:104-11

13. Akanji AO, Ezenwaka C, Adejuwon CA, Osotimehin BO. Plasma and salivary concentrations of glucose and cortisol during insulininduced hypoglycaemic stress in healthy Nigerians. Afr J Med Med Sci. 1990;19:265-9.

14. Di Gioia ML, Leggio A, Le Pera A, Liguori A, Napoli A, Siciliano $\mathrm{C}$, et al. Quantitative analysis of human salivary glucose by gas chromatography-mass spectrometry. J Chromatogr B Analyt Technol Biomed Life Sci. 2004;801:355-8.

15. Navazesh M. Methods for collecting saliva. Ann N Y Acad Sci. 1993;694:72-7.

16. Moore PA, Guggenheimer J, Etzel KR, Weyant RJ, Orchard T. Type 1 diabetes mellitus, xerostomia, and salivary flow rates. Oral Surg Oral Med Oral Pathol Oral Radiol Endod. 2001;92:281-91.

\section{Acknowledgements:}

We wish to thank the National Council for Research and Development $(\mathrm{CNPq})$ for their financial support, and the Molecular Biology Laboratory at the Federal University of Paraíba (Brazil). 